\title{
Krapp's last tape: sujeto, agotamiento y lenguaje
}

Fecha recepción: 15 de abril de 2020.

Fecha de aceptación: 28 de junio de 2020

\begin{abstract}
Resumen
En el presente artículo analizaremos el problema del sujeto en la dramaturgia de Samuel Beckett, específicamente en la pieza Krapp’s Last Tape (1958), cuestión que será abordada desde la noción de personaje dramático y fábula. Enfocándonos en la relación ontológica que sostiene el personaje con su discurso dramático, observaremos cómo el lenguaje se constituye como su única posibilidad de existir, cuestión problemática en tanto la subjetividad de Krapp es desbordada por las diferentes voces que emergen de sus cintas. En su agotamiento, el personaje se encuentra situado en una 'encrucijada de palabras', donde su monólogo se repliega constantemente sobre sí mismo, construyendo una situación estático-dinámica. Escenario que invierte el movimiento temporal en la obra, pues este se configura desde la constante retrospección al pasado y los recuerdos del personaje, en un ritmo errático que tiende a la circularidad e instala un presente perpetuo, la espera de un final que no termina de acabarse.
\end{abstract}

Palabras clave: Beckett, subjetividad, monólogo, personaje, fábula.

\section{Krapp's last tape: subject, exhaustion and language}

\begin{abstract}
In this article we will analyze the problem of subject in the dramaturgy of Samuel Beckett, specifically in the play Krapp's Last Tape (1958), an issue that will be approached from the notion of dramatic character and plot. Focusing on the ontological relationship that the character maintains with his dramatic speech, we will observe how language is constituted as their only possibility to exist, a problematic question as Krapp's subjectivity is overflowed by different voices that emerge from his tapes. In his exhaustion, the character finds himself situated at a 'crossroads of words', where
\end{abstract}


his monologue constantly folds back on itself, constructing a static-dynamic situation. A set-up that inverts the temporal movement in the play, as it is configured from the constant retrospection to the past and the memories of the character, in an erratic rhythm that tends to circularity and installs a perpetual present, waiting for an ending that does not end to materialize.

Keywords: Beckett, subjectivity, monologue, character, plot.

\section{Introducción}

La pregunta que se formulase Maurice Blanchot en torno a ¿Q Quién habla en los libros de Samuel Beckett?' es un cuestionamiento que resuena en el horizonte de nuestro trabajo, en tanto dicha reflexión parece vincularse con algunas de las problemáticas que nos plantea Krapp's last tape (1958). Las interrogantes que complementan esta pregunta inicial, se suceden y complejizan la reflexión que nos presenta Blanchot sobre Beckett en El libro que vendrá (1979).

¿Quién habla en los libros de Samuel Beckett? ¿Cuál es ese 'Yo' incansable que, aparentemente, ¿dice siempre la misma cosa? ¿Qué fin persigue? ¿Qué espera el autor que en alguna parte ha de encontrarse? ¿Qué esperamos nosotros cuando estamos leyendo? A menos que él haya entrado en un círculo donde gira oscuramente, arrastrado por la palabra errante, no carente de sentido sino de centro, que no empieza ni termina, sin embargo ávida, exigente, que no se detendrá nunca, cuya detención no podría admitirse, porque entonces habría que hacer el terrible descubrimiento de que, cuando no habla, sigue hablando, cuando se interrumpe, está perseverando, y de ningún modo silenciosa, porque en ella, eternamente, el silencio se habla" (1979, p. 237).

La cita preliminar nos introduce de inmediato en un punto central para nuestro análisis, el cual comprende el problema de la subjetividad y el lenguaje en Krapp's last tape (1958), cuestión a la que me aproximaré desde la teoría dramática y la filosofía del sujeto, para así caracterizar el estatuto con que se nos presentan las categorías de fábula y personaje al interior de esta pieza. Desde una perspectiva dramática, el corpus teórico con el que trabajaremos tiene como marco general la reflexión de Jean-Pierre Sarrazac, en conjunto con el Institut de Recherche en Etudes Théâtrales, Université Sorbonne Nouvelle, a la que se suman aportaciones relevantes como las de Jean-Pierre Ryngaert, Robert Abirached y Joseph Danan. Por otra parte, integraremos diferentes perspectivas filosóficas que abocan su discusión a la relación lenguajesujeto, entre las que se cuentan la reflexión de Alain Badiou, el propio Blanchot, y el filósofo chileno Sergio Rojas. A su vez, complementaremos nuestro análisis con diferentes perspectivas críticas que han estudiado esta obra y su problemático personaje. Si bien la separación entre estos enfoques no es tajante, podemos reconocer al menos cuatro orientaciones predominantes: crisis del sujeto, memoria, psicoanálisis y maniqueísmo. En primer término, la crisis del sujeto puede ser delineada a partir de la reflexión de Sylvie Henning (1980) a propósito del conflicto identitario entre Krapp sus dobles, quiebre que instala un diálogo de similitudes y diferencias entre el personaje y el yo contenido en sus cintas. Esta discusión será retomada por Gordon (1990), Lawley (1994), Herren (2001), Kakiguchi (2004), Iwata (2008) y Locatelli (2008), remarcando el rol de Krapp como autor y editor de sus cintas, ejercicio de grabación autobiográfica que, en su devenir infinito, ha terminado por minar y destruir la subjetividad del personaje. Cabe agregar lo propuesto por Wulf (1993) y Catanzaro (1999), quienes se detienen en la paradójica renuncia del personaje al 
mundo exterior, pues esta convive con el deseo insatisfecho de vínculo con un otro y termina por sumir su futuro en la frustración y el fracaso. Sin abandonar la discusión en torno a la descomposición del personaje y su fracaso identitario, los estudios sobre memoria se centran sobre todo en el análisis de la relación entre memoria voluntaria e involuntaria, marco de reflexión proustiana desde donde se estudian los vínculos y resonancias de la producción literaria de ambos autores. A través del análisis comparado, Malkin (1997) analiza las diferencias entre Krapp's Last Tape y Not I a propósito de las nociones de discurso, personaje y memoria, haciendo evidentes las formas particulares de presentar el acto de recordar en cada obra. En esta línea, Ackerley (2009) y Rauschenberg (2017) interpretan la oposición entre memoria voluntaria e involuntaria desde la estética del fracaso y el mal de archivo respectivamente, en tanto la exhumación de recuerdos monocromáticos/cosificados en las cintas, no trae consigo la conquista exitosa del pasado por parte de Krapp. Desde el psicoanálisis, Julie Campbell (1997) nos ofrece un exhaustivo rastreo de las connotaciones escatológicas y humorísticas contenidas en la semántica del término 'crap', en función de la construcción de un espacio teatral que subvierte las restricciones político-sociales presentes en la cultura. Por su parte, Kintzele (2013) estudia la relación edípica de Krapp con su madre, fantasía que estaría detrás de la castración que incapacita al personaje. En lo referente a las lecturas 'maniqueístas', Knowlson (1976) presenta una recopilación y análisis de las transformaciones de la obra desde su estreno, así como diferentes comentarios introducidos por Beckett que nos permiten observar cómo la pieza se construye a partir de la oposición-integración de valores blanco/negro, siendo esta una forma de representar contrastes entre lo intelectual-espiritual y lo sensual-físico. Por su parte, Sue Wilson (2002) nos ofrece una lectura que interrelaciona la crítica de Beckett y San Agustín respecto a las incoherencias de la doctrina metafísica-esotérica maniqueísta. Habiendo reseñado sumariamente el campo crítico respecto a esta obra, cabe declarar nuestra cercanía teórica e interpretativa con el primero de los enfoques referidos: la crisis del sujeto, cuestión que no imposibilita la inclusión de otras referencias en el corpus de este artículo. A partir de un exhaustivo análisis de Krapp como entidad e identidad, esta línea interpretativa somete a observación el estatuto problemático con que este se nos presenta, enfatizando sobre todo la problemática relación entre el personaje y su discurso. En ese sentido, nuestra propuesta de lectura sobre Krapp's Last Tape, plantea que esta puede ser entendida como una escritura del cogito, en tanto el vínculo que sostiene el personaje con su discurso exhibe y da cuenta de una problemática dependencia de este respecto a sus palabras. Según Abirached, el personaje dramático puede ser entendido como "un ser de palabras, que vive en cuanto se dice a sí mismo a través de preguntas y respuestas, de cuchicheos y de gritos, de expansiones y de silencios calculados" (1994, p. 26), afirmación que de inmediato instala la soberanía del lenguaje respecto a la figura dramática, donde este se constituye como su única e irremediable posibilidad de ser. Krapp establece una relación ambivalente con sus palabras, cuestión que enuncia una paradoja, pues su monólogo termina por configurarse como una instancia donde confluyen múltiples voces en el sujeto y nos permite caracterizar su figura como un impersonaje. Recuperando la reflexión de Blanchot a propósito de este $y o$ arrastrado por una palabra errante, cabe señalar que Krapp no logra decirse a sí mismo, sino que es arrollado por su monólogo, a un punto tal que el personaje parece desvanecerse en su (im)propio discurso, sin lograr reconocerse ni sujetarse en y por él. En este sentido, el yo surge como una instancia constantemente abierta y diseminada en cada uno de los cuerpos significantes que componen este espacio de habla, haciendo imposible la constitución de una identidad estable. Esta palabra que 'no carece de sentido, sino que de centro', sitúa al personaje beckettiano en un círculo interminable donde la constatación de su existencia pasa por la obligación de hablar y decir, por lo que el silencio es una instancia imposible de alcanzar. 


\section{La dramaturgia de Samuel Beckett: aproximaciones en torno a las categorías de fábula y personaje}

Recogiendo la teorización desarrollada por Peter Szondi en el ensayo Teoría del drama moderno (1954) a propósito de la crisis del drama, cabe señalar que, desde finales del siglo XIX, se ha ido produciendo un profundo cuestionamiento y problematización del género dramático entendido como forma absoluta. En cuanto 'entidad absoluta' que se origina desde el diálogo, el tiempo se configura como un presente en constante devenir, por lo que cada momento debe dar paso a la escena siguiente, siempre de acuerdo a preceptos propios de una lógica causal que proyecten la acción hacia su desenlace en conjunto. Dicho modelo sufre una serie de transformaciones, en tanto categorías centrales del género como la de fábula y personaje, son sometidas a una profunda problematización por parte de los dramaturgos y sus obras, situación bajo la que subyace una profunda discusión en torno al lenguaje como medio de expresión y representación de la realidad. La fábula comienza a ser desestabilizada de su lugar central en el drama, el cual ocupase desde que Aristóteles catalogara la 'estructuración de los hechos' como el alma de la tragedia. En su variante aristotélico-hegeliana, los acontecimientos al interior de toda pieza dramática debían estar organizados de acuerdo a criterios de verosimilitud y necesidad, para que así la acción imitada fuese completa (principio, medio y fin). Sin embargo, dicha lógica causal y teleológica que el Estagirita asociase al concepto de fábula, sufre una progresiva descomposición, al punto que, en el drama contemporáneo, "la noción de situación tiende a dominar a la de acción" (Sarrazac:2013, p. 94). La crisis de la fábula que plantea Sarrazac, da cuenta de cómo el 'sistema de hechos' que estructurase orgánicamente una pieza en torno a la unidad de acción, comienza a deshacerse en el devenir del drama moderno y contemporáneo, cuestión que se materializa en un "desarrollo errático, incluso anárquico y, en cierta medida, teratológico de la fábula -o de lo que queda de ella-" (Sarrazac:2011, p. 29). El tiempo ha sufrido un importante cambio en su orientación, las agujas del reloj invierten su sentido, por lo que el movimiento proyectivo cede su lugar a una escena que es invadida por un tiempo retrospectivo donde el personaje se ubica como un testigo desdoblado respecto a sí mismo. Por otra parte, la crisis del personaje dramático presenta importantes vínculos con la noción de acción recién remitida, por lo que el cuestionamiento de uno de dichos elementos, termina por impactar en el otro. Robert Abirached establece un vínculo indisoluble entre el personaje y el mundo externo al drama, 'huella de lo real' que hace del personaje dramático la expresión material de "una imagen del mundo, de la sociedad y de los hombres" (1994, p. 24). Por dichos motivos, Abirached señala que el personaje se constituye como un conjunto de signos abierto a lo real y lo imaginario, por lo que su condición de existencia dramática es más bien inestable.

Si se puede vislumbrar, en este punto de nuestro análisis, una condición del personaje, no se puede definir más que como un conjunto de relaciones (entre la imagen y el mundo, el lenguaje y la palabra, la representación y el sentido) a la vez constantes y, en cuanto a su aplicación, susceptibles de funcionar de las más variadas maneras, en consonancia con los cambios históricos, ideológicos y estéticos que las mismas contribuyen a engendrar (1994, p. 31).

Construido como una suma de diferentes significantes, la constitución del personaje dramático está en estrecho vínculo con la imagen del individuo que se fragua en una sociedad y contexto histórico, que en este caso está dado por la modernidad. La 'crisis de mundo' que se cierne sobre la civilización occidental con posterioridad al período de entreguerras, tiene una de sus modulaciones en una desconfianza para con el mundo construido por la razón instrumental y la voluntad del individuo. Por extensión, la constitución del personaje dramático sufre importantes afectaciones, por lo que este 'ser de palabras' es sometido a un profundo cuestionamiento en sus 
dimensiones constitutivas, así como en su relación con el lenguaje. En dicho sentido, en Krapp's Last Tape nos encontramos con una pieza donde el discurso dramático se ha desligado del diálogo, siendo impulsado totalmente hacia el monólogo, construyendo así una situación comunicativa que entra de lleno al territorio de lo íntimo, asumiendo el despliegue de un espacio de habla donde el personaje, "ya no es capaz de definirse y actuar en y por medio de un lenguaje construido" (Hausbei y Heulot:2013, p. 138). Perspectivas críticas como las de Badiou, Sarrazac y el filósofo Sergio Rojas, han presentado interesantes observaciones respecto al estatuto que ocupa el lenguaje y el sujeto al interior de la obra beckettiana, así como sus ramificaciones en nociones como la de personaje dramático y fábula. La caracterización que Badiou establece en torno al personaje beckettiano señala que, en su generalidad, este "no deja de ser, en todo momento, aquel que dispone de un trayecto, una identidad, un parloteo cruel" (2007, p. 17). Reducido a tres funciones inalienables, el personaje en Beckett parece encontrarse en una encrucijada donde sus posibilidades se reducen a: movimiento, ser y lenguaje. Krapp's Last Tape nos pone frente a la intimidad del personaje dramático, siendo espectadores de su peregrinación psíquica, la cual se estructura desde la instancia de espera, configurando esta como un 'motor inmóvil'. Beckett posiciona al personaje dramático en un instante (eterno) donde este parece hallarse siempre "en una única y última estación" (Sarrazac:2011, p. 96) que nunca termina de acabarse. En dicho panorama, la dramaturgia beckettiana es una patente expresión de la fragmentación y debilitamiento del yo como consciencia racional, cuestión de la que da cuenta la ruinosa condición en la que se encuentran muchos de sus personajes. El lenguaje juega un papel fundamental en dicha circunstancia, en tanto se configura como el último espacio de residencia del sujeto, al mismo tiempo que emerge en escena como una voz infatigable sin principio ni fin. Relación ambivalente donde el discurso despoja al personaje de sí mismo, a la vez que representa su única y problemática posibilidad de constitución y existencia, en tanto el lenguaje aparece como espacio (potencial) del ser. La crisis del personaje pasa entre otras cosas, por "la distancia entre la voz y el discurso que pronuncia, en la dialéctica cada vez más compleja entre una identidad que se echa de menos y unas palabras de orígenes diversos" (Sarrazac:2013, p. 169) que se cruzan en la escena. Dicha fractura es conceptualizada por Sarrazac como una "encrucijada de palabras" (2013, p. 170), que en el caso beckettiano se movilizan sin centro, construyendo una situación dramática que se cierra sobre sí misma, en tanto el lenguaje se desplaza ávidamente, pero sin arribar a ninguna parte. Recuperando la noción de escritura del cogito antes planteada, cabe señalar que esta pieza desmantela la certeza cartesiana del 'Pienso, luego existo'. El irremediable desplazamiento del lenguaje deviene el cogito en una tortura autorreflexiva interminable, donde el personaje se agota en cuanto sujeto, obligándole a decirse y escucharse sin posibilidad de reunificar su consciencia en el silencio y acallamiento de sus voces.

\section{Krapp's Last Tape: sujeto, agotamiento y lenguaje}

La obra nos presenta a Krapp, su personaje 'único', quien se constituye como un solitario anciano de 69 años que se encuentra recluido en un ruinoso cuchitril. Este lugar establece el marco escénico en el que se desarrollará la pieza, configurándose como un espacio oscuro y casi vacío donde el personaje pasa el tiempo grabándose y escuchando su (im)propia voz, a través de un micrófono y un magnetófono. Krapp's Last Tape se estructura a partir de una situación dramática estático-dinámica de carácter circular que se inicia con Krapp sentado de frente a la mesa donde se encuentra el magnetófono, siendo de inmediato caracterizado como "a wearish old man" (Beckett:2012, p. 213). Luego de una serie de acciones pseudo rituales y maquinales, procede a buscar la caja número tres, en cuyo interior está la cinta número cinco, la cual nos permitirá escuchar la voz de Krapp treinta años antes, es decir, a sus 39 años. Antes de escucharse, 
Krapp hojea un libro donde apunta y resume los temas de cada grabación, una suerte de registro nemotécnico suplementario respecto a las cintas. Previo a iniciar la reproducción de la grabación, el personaje adopta una postura solemne, inclinándose sobre el magnetófono, tomando una clara posición de oyente y testigo respecto de sí mismo. Como observaremos más adelante, estas cintas funcionan como una suerte de espejos para el personaje, quien, en este caso, escucha cómo emerge la voz recia de un segundo Krapp treinta años más joven, el cual rememora, comenta y crítica ciertos episodios y acontecimientos del pasado. Este segundo Krapp nos permite reparar en el carácter solemne que impregna las grabaciones de estas cintas, pues el personaje lleva a cabo esta actividad el día de su cumpleaños. Ahora bien, antes de proceder a grabar, Krapp cumple la rutina de previamente escuchar una cinta anterior, cuestión que él mismo denomina como sus 'siniestras exhumaciones': "Ah well.... [Pause.] These old P. M.s are gruesome, but I often find them - [KRAPP switches off, broods, switches on. $]$ - a help before embarking on a new ... [hesitates] ... retrospect" (2012, p. 215). El 'juego' autorreflexivo se despliega de inmediato, en tanto este segundo Krapp de 39 años, remite a su vez a otra cinta en cuestión, la cual aloja en su interior los registros de un tercer Krapp diez o doce años más joven, por lo que su edad sería aproximadamente 28 años. La actitud que sostiene Krapp a sus 69 y a sus 39 años, es de profunda distancia respecto a esta anterior proyección de sí mismo, cuestión que se materializa en burlas respecto a este "cretino", quien, a su vez, también habría criticado a (un) otro Krapp aún más joven. A partir de este punto, de inmediato se tensiona el propio título de la pieza, pues nada nos asegura que esta "última" cinta de la que somos testigos, será realmente la que clausure esta estructura cuasi interminable. Atravesado por la división y la distancia respecto a sí mismo, el anciano Krapp se constituye como una figura dramática que se divide en al menos cuatro sujetos distintos, escisiones de su subjetividad que emergen a partir de esta cinta número cinco.

\section{Krapp: ¿figura única?}

Krapp’s last tape se constituye como una pieza dramática de un solo cuadro con un único protagonista que "is consumed by two machines -his pocket-watch and his tape recorder- both of which make up his obsession with clock and calendar time (Weiss:2013, p. 31). La didascalia inicial enmarca la situación dramática en "Krapp’s den" (2012, p. 213), nominación a partir de la cual se introduce esta figura única, omitiendo un listado de personajes. La ausencia de un elemento tan recurrente en el drama tradicional como el dramatis personae, comprende un rasgo propio del drama contemporáneo. La presencia de dicho listado traza de manera "casi transitiva el esquema actancial de la obra que anuncia" (Ryngaert:2016, p. 57), por lo que la falta de este, es también una marca que da cuenta de un drama que ha abandonado la acción dramática completa como su principio rector. En este sentido, podemos incluso catalogar inicialmente esta pieza como un teatro de la palabra, en tanto el personaje dramático se transforma en un tejido de diferentes voces que atraviesan la escena. Krapp cultiva una problemática relación con la palabra y el lenguaje, en tanto su excesiva compulsión a hablar le debilita identitariamente, a la vez que dicho despliegue performativo, es también su única e irremediable posibilidad de ser. Por sus características estructurales, el discurso dramático en Krapp's Last Tape se organiza desde el monólogo, por lo que el lenguaje se consagra en pos del despliegue de un espacio de habla que da lugar a la expresión y aparición de lo íntimo, es decir, a la propia psiquis del yo. El solipsismo de Krapp abre la escena al yo errante, es decir, "se desarrolla un teatro de voces supra o infrapersonales, en que 'eso' habla de lo más profundo, en lo íntimo, sin que esas voces sean de sujetos identificables en un mundo determinado" (Treilhou-Balaudé:2013, p. 112). La pieza nos ofrece una representación de aquellas fuerzas del 'adentro' que residen en el sujeto, buscando sumergirse en los niveles más profundos y subterráneos de la consciencia. La 
aparición de lo íntimo al interior del teatro provoca un golpe y tensión a los principios del drama moderno, en tanto obras como estas, no nos ofrecen "la representación del hombre en sociedad" (2013, p. 111), sino que nos sumergen en la interioridad de un sujeto intentando pensarse y decirse. La didascalia que abre la pieza nos entrega importantes claves respecto al 'conflicto' interno que reside en la subjetividad del personaje, en tanto este se posiciona de frente a la mesa sobre la que se ubica el magnetófono.

Front centre a small table, the two drawers of which open towards the audience. Sitting at the table, facing front, i.e. across from the drawers, a wearish old man: KRAPP (...) On the table a tape-recorder with microphone and a number of cardboard boxes containing reels of recorded tapes. Table and immediately adjacent area in strong white light. Rest of stage in darkness. KRAPP remains a moment motionless, heaves a great sigh, looks at his watch, fumbles in his pockets, takes out an envelope, puts it back, fumbles, takes out a small bunch of keys, raises it to his eyes, chooses a key, gets up and moves to front of table. (2012, p. 213).

Este enfrentamiento con la máquina parlante materializa el conflicto interno del personaje consigo mismo, el cual se representa a partir de las voces que emergen de sus cintas. El profundo suspiro, así como la acción de mirar el reloj, acto que Krapp repite con posterioridad en la obra, dan cuenta "that he is controlled by time and paralysed by the past (...) Ultimately, both Krapp's gesture of looking at his pocket-wash and his listening to the tape illustrate Krapp's obsession with time (Weiss:2013, p. 32). A partir de lo anterior, es posible vincular esta pieza a la noción de 'monodrama polifónico' propuesta por Joseph Danan, en tanto se escenifica el "drama de uno solo, pero con múltiples voces” (2013, p. 134). La psiquis del individuo Krapp se encuentra atravesada y asediada por diferentes voces y perspectivas, en tanto el monólogo termina por desbordar su subjetividad, formando un caótico diálogo a partir del cual no es posible reconstruir su identidad. Krapp's last tape expresa la fragmentación del personaje dramático a través de sus cintas, las cuales contienen y dispersan las memorias de su pasado: "Using the tape recorder as a journal and a photo album, Krapp tries to order his life and construct a history out of the past" (Weiss:2013, p. 32). Sylvie Henning nos señala que Krapp "is trying to achieve an integral, totalized personality" (1980, p. 97), siendo este un propósito que no logra alcanzar, pues su subjetividad no puede sustraerse del devenir transformador-destructor del tiempo, por lo que "self-identity appears, in Beckett's Works, as a futilely sought-after chimera” (1980, p. 97). La relación que Krapp sostiene con las voces que emergen de estas cintas configura un diálogo donde el sujeto no logra reconocerse en sus dobles, pues, aunque estos representen los diferentes estadios y aristas de un individuo, su subjetividad se ha diseminado en el tiempo y el lenguaje, siendo las cintas su registro y causa: "Thus, Krapp's present being in unstable and fragile; it is impossible to him to be as full as being" (Kakiguchi:2004, p. 160). El desgaste que el devenir temporal imprime sobre el sujeto, es sugerido a través de diferentes detalles, los que indirectamente van potenciando la configuración del tiempo como una fuerza destructiva. La didascalia inicial es uno de estos casos:

\author{
Rusty black narrow trousers too short for him. Rusty black sleeveless waistcoat, four \\ capacious pockets. Heavy silver watch and chain. Grimy white shirt open at neck, no \\ collar. Surprising pair of dirty white boots, size ten at least, very narrow and pointed. \\ White face. Purple nose. Disordered grey hair. Unshaven. \\ Very near-sighted [but unspectacled]. Hard of hearing. \\ Cracked voice. Distinctive intonation. Laborious walk (2012, p. 213).
}

Krapp se configura como un individuo físicamente ajado y deteriorado, a partir de varios signos que dan cuenta del paso del tiempo. Como plantea Weiss, Krapp se enfrenta al pasado con la pretensión de dominarlo a partir de la construcción de un registro y memoria autobiográfica. Sin embargo, "There is no escape from yesterday because 
yesterday has deformed us, or been deformed by us" (Beckett cit. en Weiss:2013, p. 34). El devenir temporal se marca a través de las vestimentas del personaje, destacando así lo inapropiado de estas prendas para la complexión actual de Krapp, pues no se ajustan a su talla o se encuentran desgastadas por el uso. Se hace hincapié en ciertos rasgos físicos que expresan una vejez ruinosa, como su pelo gris en desorden, y sobre todo la afección que ha sufrido en sus sentidos, en tanto Krapp ve y escucha con dificultad, además de tener una voz cascada a sus 69 años. Esta voz desgastada contrasta con el momento en que se reproduce la cinta número cinco, de donde emerge la voz del segundo Krapp, en la 'cresta de la ola'. Para Iwata, en esta obra son borroneados los bordes entre subjetividad humana y espacialidad, en tanto el cuchitril y las vestimentas del personaje, 'corporizan' y espejean la devastación del personaje (2008: cfr. p. 39).

Tape: [Strong voice, rather pompous, clearly Krapp's at a much earlier time.] Thirtynine today, sound as a-[Settling himself more comfortably he knocks one of the boxes off the table, curses, switches off sweeps boxes and ledger violently to the ground, winds tape back to beginning, switches on, resumes posture.] Thirty-nine today, sound as a bell, apart from my old weakness, and intellectually I have now every reason to suspect at the... [hesitates] ... crest of the wave-or thereabouts (2012, p. 214-215).

La tortuosa relación que establecen sus personajes con la palabra es una de las principales obsesiones que cruzan la obra de nuestro autor, lo que no es de extrañar si consideramos que Beckett fue más bien un pensador escéptico respecto a las capacidades del lenguaje a la hora de captar la realidad. Como señala Linda Ben-Zvi, Beckett fue un asiduo lector de la obra de Fritz Mauthner: "there is only language. What we commonly refer to as thinking is merely language seen from a different vantage point; thinking and speaking are one and the same activity" (1980, p. 188). El pensamiento y por extensión la percepción individual, se encuentran mediadas irremediablemente por el lenguaje, por lo que no logramos acceder a la realidad más que a través de una aproximación que se construye desde y por él.

All man can hope to gain is a representation or an approximation of reality. The heart of Mauthner's avowed skepticism come from his impossibility of ever grasping more. He is finally brought to the conclusion that there is no certainty of anything. No matter how much man wishes to gain a certainty, he can never move beyond memory and the subsequent distortions that it imparts to language (1980, p. 190).

Si lo único que podemos alcanzar a través de las palabras no es más que una aproximación incierta a las cosas mediada por el lenguaje, se abre una profunda escisión entre el sujeto y el mundo, así como entre el sujeto de la enunciación y su propio enunciado, la cual es generada "por las mismas palabras que debían nombrar y allanar el mundo" (Rojas:2013, p. 43). En tal escenario, nos ubicamos de lleno en el concepto escritura del cogito propuesto por Sergio Rojas, reflexión que si bien tiene por objeto la trilogía narrativa compuesta por Molloy, Malone Meurt y L'Innomable, creo que puede ser extendida a cierta parte de la producción dramática beckettiana. En este sentido, es posible caracterizar Krapp's Last Tape como una escritura del cogito, en tanto la subjetividad de Krapp como personaje es desbordada y avasallada por su (im)propio discurso. La lógica representacional que subyace bajo el axioma cartesiano "Pienso, luego éxito" termina por sucumbir ante el despliegue errático y excesivo del monólogo. En el Discurso del Método (1637), Descartes encuentra certidumbre de su existencia racional, en tanto:

Queriendo yo pensar que, de esa suerte, que todo era falso, era necesario que yo, que lo pensaba, fuese alguna cosa; y observando que esta verdad: $<<$ yo pienso, luego soy >>, era tan firme y segura (...) juzgué que podía recibirla, sin escrúpulo, como el primer principio de la filosofía que andaba buscando (1997, p. 68). 
El pensar afirma la existencia del sujeto en un proceso de autoconsciencia de sí mismo, donde este debe reconocerse como pensante, pensador y pensado al mismo tiempo. Sin embargo, Krapp's Last Tape hace estallar dicha lógica representacional, en tanto la figura de Krapp no logra reedificar su consciencia subjetiva, pues él se encuentra rodeado de interminables espejos en forma de cintas, epígonos de sí mismo que terminan por fragmentar su identidad (Gordon:1990 cfr. p. 99). En el asedio que representan cada uno de estos dobles, el personaje se encuentra sumido en la soledad y oscuridad de su cuchitril, consagrándose a la grabación de cintas, es decir, continúa hablando, aunque no tenga "Nothing to say, not a squeak" (2012, p. 219). El fracaso es el signo que marca las actividades de Krapp, pues no logra darse un relato y registro en el cual reconocerse y encontrarse, por lo que su búsqueda termina sumiéndole en un errático devenir.

Entre las particularidades que circundan la interacción de Krapp con su magnetófono, es significativo que el lugar donde este se encuentra sea el único espacio iluminado en escena. La asociación entre la luz y el despliegue de un espacio de habla, es un motivo que se repite en otras obras de Beckett como Play y Happy days, donde una fuente de iluminación delimita la actividad discursiva de los personajes. Krapp graba y escucha sus cintas de voz al alero de un pequeño espacio de la mesa que es alumbrado por su lámpara, siendo esa el área donde la figura dramática lleva a cabo sus siniestras exhumaciones' y estimula su intelecto ${ }^{1}$ : "The new light above my table is a great improvement. With all this darkness round me I feel less alone. [Pause] In a way. [Pause.] I love to get up and move about in it, then back here to ... [hesitates] ... me. [Pause.] Krapp" (2012, p. 215). El despliegue de este espacio de habla, da lugar a una ontología de la palabra que representa su posibilidad de salvación y condena:

His characters recognize that language is the major obstacle that makes their task virtually impossible. They keep trying to find words that will allow them to stop talking; but they continually fail. And their failure is the same failure that Mauthner describes: they cannot overcome the limitations of language" (BenZvi:198o, p. 192).

Krapp encarna una entidad e identidad que se construye y destruye en y por el lenguaje, apareciendo ante nosotros casi desprovisto de rasgos psicológico-identitarios más allá de su caracterización física, por lo que su monólogo configura "una herramienta de comunicación (...) el único recurso para reconstruir una identidad estallada" (Hausbei y Heulot:2013, p. 141). Sin embargo, dicho monólogo se configura como una palabra sobre la que el personaje ha perdido control, dando pie al despliegue de diferentes dobles que sumen a Krapp en la melancolía, por lo que "el personaje se disuelve en una palabra que más que constituirlo lo atraviesa” (2013, p. 140).

Tape: Just been listening to an old year, passages at random. I did not check in the book, but it must be at least ten or twelve years ago. At that time I think I was still living on and off with Bianca in Kedar Street. (...) These old P. M.s are gruesome, but I often find them - [KRAPP switches off, broods, switches on.] - a help before embarking on a new ... [hesitates] ... retrospect. Hard to believe I was ever that young whelp. The voice! Jesus! And the aspirations! [Brief laugh in which KRAPP joins.] And the resolutions! [Brieflaugh in which KRAPP joins.] To drink less, in particular. [Brieflaugh of KRAPP alone.] (2012, p. 215).

1. Knowlson analiza el fracaso de Krapp en la demarcación de este espacio luminoso, "the zone of light with which he would identify his essential self” (1976, p. 60), pues irónicamente, el lugar que 'preserva' su ser intelectual frente a otras pulsiones físicas, es invadido por recuerdos involuntarios y las asociaciones excrementales que rodean su propio nombre. 
Este pasaje ilustra cómo Krapp escucha a uno de sus yo del pasado, quien a su vez juzga a un Krapp anterior, movimiento autorreflexivo que debilita la constitución del personaje. Su coherencia identitaria se borronea en diferentes trazas y voces, siendo arrastrado por los recuerdos que evocan cada una de estas cintas. Resulta más que ilustrativa la reacción de risa que comparte el Krapp de 39 años con el anciano que vemos en escena, quien, a su vez, se ríe en soledad cuando la voz de la cinta menciona que uno de sus objetivos es beber menos, ya que como hemos observado, esta (aún) es una actividad que el personaje repite compulsivamente. El astillamiento es bastante profundo, pues la distancia del segundo Krapp respecto al tercer Krapp, pasa por considerar falsas las críticas que este sujeto esgrime contra un cuarto Krapp en cuestión:

Sneers at what he calls his youth and thanks to God that it's over. [Pause.] False ring there. [Pause.] Shadows of the opus ... magnum. Closing with a-[brieflaugh] - yelp to Providence. [Prolonged laugh in which KRAPP joins.] What remains of all that misery? (2012, p. 216).

El agotamiento del sujeto reside en la incapacidad de este para reconocerse en su (im) propio discurso, cuestión que marca la crisis del personaje dramático, situándolo en una 'encrucijada de palabras', imagen a partir de la cual se materializa la "fractura entre lo que es hablado y la fuente de esta palabra que no hace más que aumentar" (Sarrazac:2013, p. 169). En el caso de Krapp, la distancia que existe entre el anciano y sus dobles se exhibe como irreductible e infranqueable: "Krapp: Just been listening to that stupid bastard I took myself for thirty years ago, hard to believe I was ever as bad as that. Thank God that's all done with anyway" (2012, p. 218). Su fractura identitaria afecta las cualidades con que este aparece ante nosotros, pues Krapp no se erige como un agente a partir del cual se sostiene y proyecta la acción dramática, sino como una entidad errática, cuyo movimiento mecánico y entrecortado convive con una postura contemplativa con respecto a sí mismo, posicionándose como un testigo y recordador reflexivo: "He raises his head, broods, bends over machine, switches on and assumes listening posture, i. e. leaning forward, elbows on table, hand cupping ear towards machine, face front" (2012, p. 214). Krapp se "mira" frente a las voces que emergen de su pasado, proyecciones de sí que surgen como sus dobles: "El yo se ha diseminado en el habla descontinuada que yace contenida en aquellas cintas. El sujeto ha ingresado en el inmanente cuerpo significante de los signos" (Rojas:2013, p. 50). Inscrito en el lenguaje y en el tiempo, este es incapaz de decirse a sí mismo más que de manera provisoria, por lo que el presente de la enunciación se encuentra abierto a la totalidad, espacio donde confluyen pasado y futuro como dos instancias que no pueden ser dominadas por el sujeto. Atendamos a la siguiente cita, asociada a un momento donde el Krapp de 39 años contenido en la cinta número cinco, narra la agonía de su madre:

Tape: (...) there is of course the house on the canal where mother lay a-dying, in the late autumn, after her long viduity [KRAPP gives a start] and the - [KRAPP switches off, winds back tape a little, bends his ear closer to machine, switches on]-a-dying, after her long viduity, and the- [KRAPP switches off, raises his head, stares blankly before him. His lips move in the syllables of 'viduity'. No sound. He gets up, goes backstage into darkness, comes back with an enormous dictionary, lays it on table, sits down and looks up the word.]

KRAPP: [Reading from dictionary.] State - or condition-of being-or remaining-a widow-or widower. [Looks up. Puzzled.] Being-or remaining? ... (2012, p. 216).

El pasaje es doblemente significativo, pues a partir de este contrapunto entre Krapp y la cinta, observamos cómo a sus 69 años, el personaje no es capaz de recordar el significado de la palabra viudez. Cuestión más que problemática, pues como señalaba Weiss, a través del acto de grabar, Krapp usa "the tape recorder as a journal and a photo album, Krapp tries to order his life and construct a history out of the past" (2013, p. 32). Sin 
embargo, el personaje fracasa en el control y edición de su memoria autobiográfica, en tanto dicha memoria -que ha sido moldeada por sí mismo y se encuentra contenida en las cintas- no se sustrae de poder ser olvidada por su propio creador: "Krapp is a character stubbornly engaged in self-definition, but bound to be exhausted by this 'homework' and ridiculed for trying it" (Locatelli:2008, 73). La pregunta final planteada por Krapp resuena de forma irónica, pues este no puede darse un relato autobiográfico en el cual reconocerse y permanecer, pues es agotado por el lenguaje y el tiempo.

The more one tries to pinpoint time, to finalize meaning, or to characterize 'the complete Krapp', the more one persists in the futile endeavor of fixing Watt's dot in the center of the circle, since every effort in centering it, in a continuously moving universe, only serves to retain it in its same (comparable) distance from the center (Gordon:199o, p. 104).

Los personajes beckettianos concentran su constitución dramática en tres funciones irreductibles "el movimiento y el reposo (ir, deambular, o deslizarse, caer, yacer); el ser (lo que hay, los lugares, las apariencias y también la vacilación en toda identidad); y el lenguaje (el imperativo del decir, la imposibilidad del silencio)" (Badiou:2007, p. 17). Cuestión que autores como Hugh Kenner y Sergio Rojas han descrito como un cartesianismo beckettiano extremo, donde el sujeto no es más que reducido a restos y descomposición. Ante la imposibilidad del lenguaje por reconstituir la identidad del ser consigo mismo, el movimiento del discurso dramático termina por hacer pervivir la diseminación del yo en diferentes voces. Subjetividad agotada y desmantelada que en el caso de Krapp, se manifiesta en un yo irremediablemente disgregado en el habla contenido por las diferentes cintas grabadas a lo largo de los años:

Krapp: Just been listening to that stupid bastard I took myself for thirty years ago, hard to believe I was ever as bad as that. Thank God that's all done with anyway. [Pause.] The eyes she had! [Broods, realizes he is recording silence, switches off, broods. Finally.] Everything there, everything, all the-[Realizes this is not being recorded, switches on.] Everything there, everything on this old muckball, all the light and dark and famine and feasting of ... [hesitates] ... the ages! [In a shout] Yes! [Pause.] Let that go! Jesus! Take his mind off his homework! Jesus! [Pause. Weary.] Ah well, maybe he was right. [Pause.] Maybe he was right. [Broods. Realizes. Switches off Consults envelope.] Pah! [Crumples it and throws it away. Broods. Switches on.] Nothing to say, not a squeak. What's a year now? The sour cud and the iron stool. [Pause.] Revelled in the word spool. [With relish.] Spooool! Happiest moment of the past half million. [Pause.] (2012, p. 218-219).

Este fragmento no solo advierte de un profundo extrañamiento subjetivo, sino que también de la pretensión de control que busca tener el personaje sobre la construcción su discurso y su memoria. Pausar la grabación al percatarse que está grabando el silencio, así como repetir un parlamento que no fue grabado, dan cuenta de la galantería del personaje en relación a su discurso, aspecto que se marca en el saboreo de la palabra 'spool', instante que Krapp describe como el más feliz en casi medio millón de momentos. En su obra Detritus, también se permite un cierto goce manipulando un lenguaje que lo arrolla como sujeto. La percepción del personaje respecto al tiempo aparece aquí como una serie de islotes separados, esos millones de instantes y momentos individuales que se acumulan en medio de la oscuridad gris de su cuchitril, lugar donde Krapp pasa el tiempo escuchando y grabándose a sí mismo, un ejercicio mecánico-ritual que ha terminado por minar su constitución identitaria. Situación por lo que el ser se exhibe como "un suplemento que la prosa arrastra en el mismo lapso de tiempo en el que toda su energía se dispone a no dejar emplazamiento alguno a ningún suplemento" (Badiou:2007, p. 27). Su subjetividad se diluye y estalla en distintas voces que se terminan haciendo soberanas por sobre el personaje, quien no logra encontrarse en 
su palabra ni arribar como sujeto de su discurso, por lo que las palabras se imponen sobre él, al punto que "más que hablar, el personaje es hablado" (Sarrazac:2013, p. 171).

El sujeto es prisionero de un lenguaje agotado que da vueltas sobre un centro que no se encuentra, como un extraviado que "da vueltas en torno a..., verbo sin complemento. No gira alrededor de algo, ni siquiera de nada (...) El extraviado va hacia adelante y está en el mismo punto, se agota en desandar, sin andar, sin permanecer" (Blanchot:1996, p. 62).

En esta instancia reside la ambigüedad y el carácter problemático que se cierne sobre la figura de Krapp, en tanto se juega su existencia en relación con esta palabra soberana. Krapp busca dominar y manipular el lenguaje y la voz que emerge de las cintas, con el fin de poder configurar un retrato de sí mismo y su memoria. La voz y los recuerdos contenidos son el testimonio de su sobrevivencia, como también de su constante desplazamiento y agotamiento. En la soledad de su cuchitril, Krapp se encuentra "acompañado" de un sinfín de espejos que confeccionan el confuso paisaje de su consciencia y existencia. Recorrido que según Blanchot no tendría otro destino que el fracaso, por lo que la búsqueda del sujeto Krapp no podrá encontrar más que una voz errática, un balbuceo y murmullo que camina hacia la frustración y la imposibilidad de decirse bien, una acumulación y repetición de palabras fragmentadas que se superponen entre sí. La enunciación supone un espacio de (potencial) reconstitución, una vía hacia el silencio que nunca es alcanzado. El surgimiento de esta voz incansable que inunda todo con palabras, termina por engullir al sujeto en su monólogo, en un movimiento que aplasta la subjetividad y la desfonda en un vacío que solo encuentra el decir de las palabras.

La palabra encontrar, en un comienzo, no significa en absoluto encontrar, en el sentido del resultado práctico o científico. Encontrar es contonear el movimiento melódico, hacer que dé vueltas, que ande. Aquí ninguna idea de meta, y menos de detención. Encontrar es casi exactamente la misma palabra que buscar, lo que quiere decir: 'dar la vuelta a' (Blanchot:1996, p. 61).

Por las características de su reclusión voluntaria, el personaje carece de una percepción y reconocimiento exterior, cuestión que asoma como una preocupación importante, a raíz de las reiteradas menciones a los ojos y la mirada de los otros: "Tape: One dark young beauty I recollect particularly, all white and starch, incomparable bosom, with a big black hooded perambulator, most funereal thing. Whenever I looked in her direction she had her eyes on me" (2012, p. 217). Podemos volver a encontrarnos con una referencia similar al momento de recordar a su antigua ex novia Bianca, a quien Krapp describe como un "Hopeless business. [Pause.] Not much about her, apart from a tribute to her eyes. Very warm. I suddenly saw them again. [Pause.] Incomparable! [Pause.]" (2012, p. 215). Quizás el pasaje más ilustrativo al respecto está dado por el episodio final 'adiós al amor', situación donde Krapp recuerda una antigua relación sentimental:

Tape: I asked her to look at me and after a few moments-[Pause.]-after a few moments she did, but the eyes just slits, because of the glare. I bent over to get them in the shadow and they opened. [Pause. Low.] Let me in. [Pause.] We drifted in among the flags and stuck. The way they went down, sighing, before the stem! [Pause.] I lay down across her with my face in her breasts and my hand on her (2012, p. 219-220).

La importancia que Krapp da al sentido de la vista, tal vez ilustra antiguos deseos de restauración consigo mismo y con los otros. 
Krapps strives for the union at the very moment of separation. (...) His plea is not only-perhaps not at all- physical. (...) 'The eye', Beckett told Rick Cluchey, is 'it the organ of interruption between light and dark'. But by the same token it can also hold the promise of continuity, of union, as it does for Krapp, in the eyes of his women. 'Let me in' is a plea to heal separation and exclusion (Lawley:1994, p. 92).

Krapp inicia la reproducción de estas cintas inclinándose sobre el magnetófono, gesto que transforma "the tape recorder into something other, something human" (Weiss:2013, p. 35), humanización del objeto que parece suplir la carencia de vínculos con un otro en el cual reconocerse y que, además -en el pasaje recién citado-, se configura como un reflejo degradado de su relación sexual con esta joven.

Nos hemos detenido en la condición de existencia dramática de Krapp, la cual puede ser caracterizada desde la figura del impersonaje, en tanto este se constituye como un tejido de voces y textualidades que atraviesan la escena. Lejos de hacer desaparecer al personaje dramático y sumirlo en la 'nada', estas abren su figura una heterogeneidad de discursos. La subjetividad de Krapp "se nos presenta como el lugar de pasaje y de metamorfosis de todos esos rostros, de todas las máscaras ('desnudas') que hacen la vida de un hombre, que hacen la vida de todo hombre" (Sarrazac:2007, p. 367), por lo que ninguna de estas voces termina por construir una identidad dramática estable, sino que perpetúan un constante diferimiento que termina por agotar al sujeto. Krapp parece desintegrarse en una "letanía de varias voces contradictorias, en esta especie de monodrama polifónico, el personaje no termina de cavar -como uno cava su tumbasu propia ausencia de identidad" (2007, p. 362). Su propio nombre participa de dicha desfiguración, siendo evidentes las similitudes sonoras entre 'Krapp' y la palabra 'crap', vocabulario que remite a 'basura': "This sense of waste runs throughout the play: Krapp is like an empty husk at the end of his life, and he is sifting through his recorded past in a way which is strongly at variance with the way the younger Krapp assessed the events he recorded" (Capmbell:1997, p. 63). El término evoca tanto imágenes de acumulación como de desintegración, bajo las cuales podemos leer al (im)personaje y sus cintas. Su identidad va saltando y transformándose en el tiempo, así como su rol en el drama, en tanto es creador-editor y oyente-testigo de sus propias cintas. Incapaz de reconocerse en y por su discurso, la subjetividad de Krapp se fragmenta en diferentes voces que lejos de permitir su reconstitución identitaria, terminan por agotar al sujeto y lanzarlo irremediablemente al lenguaje, por lo que la última cinta de Krapp es un horizonte abierto (al fracaso y la errancia del ser).

\section{Situación dramática: una suma interminable de instantes}

Una idea que recorre la reflexión teórica de Abirached y Sarrazac, es que la crisis del personaje es manifestación de una crisis mayor que termina por poner en entredicho el estatuto de la mímesis al interior del drama. En dicho sentido, es interesante observar de qué forma se interrelacionan la crisis del personaje con la crisis de la fábula en esta pieza. Casi desde un inicio podemos constatar que la forma que adquiere la fábula al interior de Krapp's Last Tape se distancia bastante de lo que entendemos como una representación tradicional. Al carecer de una figura dramática dotada de agencialidad que movilice una secuencia de acción completa, la obra no se estructura de acuerdo a un principio proyectivo que se oriente en función del desenlace y/o resolución del conflicto. Por el contrario, nos encontramos con Krapp, quien se caracteriza más bien como un personaje oyente/testigo que imprime un movimiento retrospectivo a la pieza, a partir de encontrarse sumido en la rememoración de sus recuerdos. La ausencia de una secuencia de acción dramática con un principio, medio y fin determinados, nos pone frente a una pieza de corte más intimista donde nociones como la de conflicto y 
catástrofe son resignificadas a la luz de ciertas transformaciones a nivel de la fábula. Al igual que Fin de partie, Krapp's Last Tape nos presenta la 'catástrofe' como una instancia inicial e inaugural respecto al drama, funcionando como un principio movilizador de los 'acontecimientos' que tienen lugar en la pieza: "A late evening in the future. Krapp's den" (2012, p. 213). El refugio de Hamm y Clov guarda estrechas similitudes con el cuchitril de Krapp a nivel de espacio dramático, configurándose como un lugar oscuro y cerrado donde acaece la existencia del personaje, quien se define en el habitar de dicho espacio interior, respecto a un exterior 'amenazante'. Beckett construye entonces una situación dramática "después de la catástrofe" (Kuntz, Naugrette y Riviere:2013, p. 50), un futuro indeterminado donde se nos presenta al personaje en soledad, sin antecedentes previos que nos den luces de lo que ocurrió "antes" de que iniciara la pieza. La 'gran conversión' a la que remite Sarrazac -a propósito de la inversión de la catástrofe-, comprende un fenómeno en estrecha relación con el debilitamiento y redefinición de otra noción dramática fundamental, el "conflicto". El teatro contemporáneo no ha desalojado al conflicto de la sala, sino que le ha dado nuevos tratamientos temáticoestructurales que van más allá del sentido de la colisión tradicional, asociado sobre todo "a un teatro de la acción, en el cual el desarrollo de la fábula se da a través de las distintas etapas de una lucha" (Gaudé, Kuntz y Lescot:2013, p. 57). Siguiendo a Laurent Gaudé, en una pieza como Krapp's Last Tape el conflicto se vuelve el tema mismo de la obra, un aspecto central que se materializa a partir de una serie de 'combates cotidianos' que sostiene el sujeto consigo mismo, los cuales pasan por el agotamiento del personaje dramático Krapp enfrentado a sus dobles. En términos estructurales, la obra nos presenta un solo cuadro, recurso dramático que no solo imprime un movimiento dramático más pausado, sino que contribuye a crear "una focalización (...) sobre un mundo (un medio, una época) que se impone al espectador con una presencia visual y silenciosa desconocida para la abstracta dramaturgia clásica" (Losco:2013, p. 68), poniendo un énfasis y acento particular en ciertos momentos cargados de sentido. La compresión y condensación extrema que se ejerce sobre la fábula, nos permite recurrir a la noción de "Pieza-paisaje" propuesta por Joseph Danan, en tanto se nos ubica en torno a una situación dramática específica, "en el centro de un paisaje (humano, social, etc.) que es un mundo (más o menos grande) o una psique singular, un paisaje interior" (2013, p. 174). Krapp no es un personaje totalmente pasivo, posee una agencialidad limitada que se atiene a la manipulación de sus cintas de voz, ubicándose entonces como un oyente y testigo frente a estas. Dicha disposición por parte del personaje termina por impactar en la estructuración que adquiere el tiempo en la obra, configurándose como un movimiento entrecortado que tiende al estatismo, en tanto Krapp se encuentra ahí, en su cuchitril, como un espectador ante su existencia, reproduciendo y pausando los recuerdos contenidos en sus cintas.

Tape: I sat on for a few moments with the ball in my hand and the dog yelping and pawing at me. [Pause.] Moments. Her moments, my moments. [Pause.] The dog's moments. [Pause.] In the end I held it out to him and he took it in his mouth, gently, gently. (2012, p. 217).

El pasaje anterior tiene por objeto un recuerdo específico de Krapp a sus 39 años, y resulta ilustrativo respecto a la configuración que adquiere el tiempo en la obra: una espera (inacabada). Los instantes que Krapp permanece con la pelota negra en sus manos constituyen una pequeña eternidad para el perro blanco que le solicita lastimosamente dicho objeto. La espera del animal se compone de diferentes instantes, una serie de islotes temporales aislados a los que hicimos mención anteriormente, un tiempo atomizado en momentos particulares que se acumulan en un presente eterno e interminable para Krapp a sus 69 años, quien espera tal como Vladimir y Estragón, aguardando el advenimiento del final, de una nueva-última cinta. Krapp’s Last Tape nos ubica ante Krapp y el paisaje de su consciencia, la cual es desnudada en su soledad e intimidad, por lo que el yo (o su ausencia) ocupa un lugar central en 
la obra. No es casualidad que al momento de grabar su 'última cinta', Krapp vuelque nuevamente su discurso hacia un recuerdo del pasado, específicamente un momento donde abandonó su cuchitril saliendo hacia el exterior: "Crawled out once or twice, before the summer was cold. Sat shivering in the park, drowned in dreams and burning to be gone. Not a soul" (2012, p. 219). Somos testigos de los recuerdos ofrecidos por el personaje, quien se afirma y se diluye en sus palabras sin poder "terminar". La soledad física y sentimental experimentada por el personaje tanto dentro como fuera de su espacio, son complementadas por una serie de actividades bajo las que ha estructurado su vida, las cuales suplen hasta cierto punto la nula compañía que tiene. Entre dichas labores es posible contar la ingesta de plátanos y alcohol, y por supuesto, las actividades que conciernen a la máquina parlante. Sobre estas actividades (y su repetición compulsiva), la obra funda su movimiento, por lo que el carácter rutinario y maquinal de estas, configuran una situación dramática estático-dinámica: "Krapp remains a moment motionless, heaves a great sigh, looks at his watch, fumbles in his pockets, takes out an envelope, puts it back, fumbles, takes out a small bunch of keys, raises it to his eyes, chooses a key, gets up and moves to front of table" (2012, p. 213). Aun cuando "ocurren" cosas sobre el tablado en escena, es difícil poder esgrimir que estas diferentes acciones individuales se integren e interrelacionen de manera articulada y progresiva. Por el contrario, más bien constituyen una serie de movimientos maquinales que se suceden reiteradamente, presentando diferencias entre sí, pero que no imprimen una transformación a la situación dramática, sino que más bien fomentan su mantenimiento. La representación "se enrolla alrededor de este único instante, de esta secuencia casi inmóvil del 'vagabundeo' donde un durmiente se yergue, donde un hombre de pie se duerme" (Sarrazac:2011, p. 104). Este ritmo temporal entrecortado se nutre del ir y venir físico del personaje, así como de la constante manipulación que este hace de las cintas, adelantando, pausando y retrocediendo su reproducción, reforzando la dilación temporal y el establecimiento de una situación dramática estático-dinámica. Resulta ilustrativo reparar en el hecho de que el personaje interrumpe tres veces sus actividades en el magnetófono para retirarse a beber al fondo de la escena en oscuridad, momentos que si bien comprenden "una misma" acción, son ejecutados con diferencias (de las que nos enteramos por las variaciones en los ruidos que emite el personaje manipulando botellas y vasos): "[Krapp switches off, broods, looks at his watch, gets up, goes backstage into darkness. Ten seconds. Pop of cork. Ten seconds. Second cork. Ten seconds. Third cork. Ten seconds. Brief burst of quavering song.]" (2012, p. 216). Si el tiempo del drama moderno es un presente en constante devenir, una 'sucesión absoluta de presentes', la temporalidad predominante en el drama contemporáneo y en Krapp's last tape en específico, está dado por un presente que se eterniza, donde no ocurre nada que logre romper tal estancamiento. Motivo por el cual la experiencia y relación que tiene el personaje para con el tiempo está dada por la duración, configurando así un escenario temporal subjetivo donde el presente termina por estallar y abrirse al pasado $\mathrm{y}$ al futuro indistintamente

Tape: Extraordinary silence this evening, I strain my ears and do not hear a sound. Old Miss McGlome always sings at this hour. But not tonight. Songs of her girlhood, she says. Hard to think of her as a girl. Wonderful woman though. Connaught, I fancy. [Pause.] Shall I sing when I am her age, if I ever am? No. [Pause.] Did I sing as a boy? No. [Pause.] Did I ever sing? No. (2012, p. 215).

La casi total inmovilidad que domina a Krapp al momento de rememorar, contrasta con el movimiento de la cinta y de sus propias proyecciones mentales al momento de escuchar, por lo que el personaje se hunde "en la arena del tiempo y en su memoria personal; repaso reiterativo del relato de vida de este mismo protagonista" (Sarrazac:2011, p. 99). La postura adoptada por el personaje no solo termina por agotar y astillar su subjetividad, sino que impone un ritmo que está marcado por la retrospección, la cual termina por invertir el movimiento dramático, por lo que la pieza se repliega 
constantemente sobre un mismo instante (eterno). En esta situación dramática, tal como el personaje, la acción "ya no se 'desarrolla', se enrolla alrededor de este único instante, de esta secuencia casi inmóvil del 'vagabundeo' donde un durmiente se duerme, donde un hombre de pie se duerme" (2011, p. 104). La espera solitaria adquiere la forma de una agonía interminable, un espacio 'vacío' pero colmado de instantes que paradójicamente, se encuentran llenos de tiempo y por sobre todo, de lenguaje. Frente a sus recuerdos, la subjetividad se agota y desmantela, reduciendo al personaje a un agonizante que aun cuando no tienen nada que decir, está condenado a hablar sin poder alcanzar/encontrar un final o a sí mismo detrás de esas palabras: "Krapp: Ah finish your booze now and get to your bed. Go on with this drivel in the morning. Or leave it at that. [Pause.] Leave it at that. [Pause.] Lie propped up in the dark-and wander" (2012, p. 219). El carácter problemático del lenguaje tiene una importancia fundamental, en tanto el vagabundeo existencial de Krapp y su discurso, se condice a nivel estructural en un movimiento dramático errático que se vuelca constantemente sobre sí mismo. El monólogo se despliega de manera excesiva, cortando los vínculos entre enunciante y enunciado, astillamiento identitario irremediable donde el lenguaje y las palabras "circulan sin cesar y, dicho sea de una vez, van dando vueltas entre dos o varios polos" (Sarrazac:2011, p. 108). La agonía del personaje se modula a través de diferentes 'juegos' maquinales constantemente recomenzados, un diferimiento iterativo que no solo agota al personaje, sino a la acción dramática misma, la cual da vuelta constantemente sobre sí misma, imitando el movimiento de las cintas, enrollándose sobre su eje, en este caso, un presente perpetuo.

Tape: We lay there without moving. But under us all moved, and moved us, gently, up and down, and from side to side.

[Pause.]

Past midnight. Never knew such silence. The earth might be uninhabited.

[Pause.]

Here I end- [KRAPP switches off, winds tape back, switches on again.]

(...) We lay there without moving. But under us all moved, and moved us, gently, up and down, and from side to side.

[Pause.]

Past midnight. Never knew- (Beckett:2012, p. 217-218).

Krapp ejerce las labores de un editor respecto a sus recuerdos, en tanto va rebobinando, adelantando y pausando la reproducción de la cinta según estima necesario, por lo que ciertos momentos escuchados se repiten más de una vez: "Con el recurso estilístico de la repetición y la variación, Beckett logra 'dibujar', literalmente hablando, la 'discontinuidad y continuidad' del sujeto Krapp en sus individuos temporales' (Prado:2015, p. 69). Si bien el status quo sufre pequeñas variaciones, la fábula se configura en torno a una situación dramática que tiende al estatismo y la circularidad, cuyo ritmo de progresión está dado por la iteración, el espejeo y los diferentes desdoblamientos del personaje.

En una segunda variación, el teatro se da simplemente por lo que es, como un juego sin principio ni fin, regulado hasta sus últimas peripecias y encerrado para siempre en su propia reproducción. Es lo que yo llamaría un teatro del teatro, cuyo texto y su comentario los proporciona la vida, percibida ella misma como una comedia de sombras sobre un escenario fantasma. En ese sentido, no existe teatro sino en segundo grado, como dan a entenderlo por sí solos la mayoría de los títulos de Samuel Beckett: Final de partida, La última cinta, Comedia, Acto sin palabras, Film, Aliento. Todo está actuado desde antes de la representación, en una esfera cerrada donde la teatralidad no puede sino venir a encerrarse a su vez. $<<$ Acabado, se ha acabado, se va a acabar, quizás se va a acabar>> dice Clov cuando se alza el telón (Abirached:1994, p. 404). 
A lo largo de este artículo, nos hemos detenido en caracterizar el funcionamiento del discurso dramático en esta obra, el cual termina por construir la partitura de un epílogo interminable, una composición que se reanuda una y otra vez hasta la saciedad. El signo que parece sintetizar Krapp's Last Tape está dado por el fracaso, instancia que marca el camino sostenido por el personaje y su discurso dramático, en tanto sus (im)propias voces dan vuelta sobre sí mismas en la cinta magnética, del mismo modo que la situación dramática se enrolla sobre esta errancia. La búsqueda de sí mismo por parte del personaje deviene en un movimiento vagabundo que no transforma la situación inicial, sino que ingresa en un esquema beckettiano de repetición y diferencia. La sucesión de diferentes acciones individuales si bien imprime movilidad a los acontecimientos, no logra articular un arco de progreso y desarrollo dramático que resuelvan el 'conflicto' puesto en escena.

KRAPP remains a moment motionless, heaves a great sigh, looks at his watch, fumbles in his pockets, takes out an envelope, puts it back, fumbles, takes out a small bunch of keys, raises it to his eyes, chooses a key, gets up and moves to front of table... (...) takes out a large banana, peers at it, locks drawer, puts keys back in his pocket. He resumes his pacing, finishes banana, returns to table, sits down, remains a moment motion less, heaves a great sigh, takes keys from his pockets, raises them to his eyes, chooses key, gets up and moves to front of table, unlocks second drawer, takes out a second large banana, peers at it, locks drawer, puts back keys in his pocket, turns, advances to edge of stage, halts, strokes banana, peels it, tosses skin into pit, puts end of banana in his mouth and remains motionless, staring vacuously before him. (2012, p. 213).

Para finalizar, es importante recalcar que Beckett fue un pionero en el uso de este tipo de artefactos tecnológicos en el drama. Sin duda es significativo que nos sitúe como espectadores de este Krapp y sus 'siniestras exhumaciones', pues bajo la escenificación de esta relación hombre-máquina se perfila una potente reflexión sobre el drama, el sujeto y la memoria. La dramaturgia beckettiana constantemente va excavando los principios y categorías centrales del género, una "siniestra exhumación" que busca precisamente desnudar el drama y sus elementos constitutivos, exhibiendo así su dimensión material, es decir, una construcción discursiva que se sostiene en y por el lenguaje.

\section{Conclusión}

Ubicados en diferentes espacios de aislamiento-reclusión y afectados por diferentes padecimientos físicos, los personajes que habitan la dramaturgia beckettiana comparten además un rasgo inalterable: una irremediable propulsión a hablar. Ya sea a través de falsos intercambios dramáticos, o lisa y llanamente desde el monólogo, la dramaturgia beckettiana sitúa al personaje y su subjetividad en el lenguaje, dimensión desde la que resiste a los diferentes asedios desplegados por Beckett sobre la figura dramática. Reducido a voces y palabras, (lo que queda del) sujeto continúa hablando todavía, sobreviviendo aferrado a un discurso que lo domina, pero que también le ofrece su única y problemática posibilidad de existir. Ambivalencia que se inscribe en un proceso de descomposición y recomposición infinita donde el personaje pervive en la valiente acción de hablar, aún cuando no hay nada más allá del lenguaje. Como última traza de subjetividad en su devenir impersonal, esta encrucijada de palabras es la instancia donde pervive el personaje en su agotamiento, atravesado por una voz sin principio ni final que desborda su identidad, y vuela en busca de interlocutor. Tal como Clov anhela el silencio frente a un lenguaje que no parece permitirle significar 'algo', la existencia dramática de Krapp se ve recluida a la repetición de su fracaso, situación de la que el personaje es consciente. A través de estas 'imágenes' huidizas, el teatro beckettiano "es 
un teatro 'del devenir', una descomposición que se mueve hacia la recomposición, en sí misma descomponiéndose. Es un teatro de perpetuo movimiento o flujo de idas y venidas" (Gontasrki:2015, p. 16). La canción que Krapp interpreta nos dice "Now the day is over, Night is drawing nigh-igh, Shadows-" (2012, p. 216), versos que refieren a unas sombras que no han terminado de traer la noche aun cuando se ha acabado el día, un final que no termina de llegar, una agonía dilatada que se materializa como la espera de una última cinta que es siempre la siguiente. 


\section{Bibliografía}

" Abirached, R. (1994) La crisis del personaje en el teatro moderno. Madrid: Publicaciones de la asociación de directores de España.

"Ackerley, C. “'The past in monochrome': (In)voluntary memory in Samuel Beckett's Krapp's Last Tape" en (2009) D., Guardamanga y R., Sebellin (Eds.) The Tragic Comedy of Samuel Beckett. Roma: Universita degli Studi di RomaEditorial Laterza, 277-291.

»Badiou, A. (2007) Beckett. El infatigable deseo. Madrid: Arena Libros.

» Beckett, S. (2012) The Complete dramatic Works. London: Faber \&Faber [ebook].

" Ben-Zvi, L. "Samuel Beckett, Fritz Mauthner, and the Limitis of Language". en (1980). Modern Language Association. Nº5, 183-200

»Blanchot, M. (1979). El libro que vendrá. Caracas: Monte Ávila.

» Blanchot, M. (1996) El diálogo inconcluso. Caracas: Monte Ávila

»Campbell, J. “The semantic Krapp in 'Krapp's Last Tape’” en (1997) Samuel Beckett Today/ Aujourd'hui, Vol. 6, 63-72.

»Catanzaro, M. "What It Means to Be a Man: Aging and Anxiety in Beckett's Krapp's Last Tape and That Time”. En (1999) Journal of Aging and Identity. N ${ }^{\circ}$ 4, 13-31.

»Danan, J. “Monodrama (polifónico)" en (2013) J.P. Sarrazac (Dir.) Léxico del drama moderno y contemporáneo. México: Paso de Gato, 134-136.

»Danan, J. “Pieza-paisaje” en (2013) J.P. Sarrazac (Dir.) Léxico del drama moderno y contemporáneo. México: Paso de Gato, 173-174.

»Descartes, R. (1997) Discurso del método/ Meditaciones metafísicas. Madrid: Editorial Espasa Calpe.

» Gaude, L, H. Kuntz y D. Lescot. “Conflicto” en (2013) J.P. Sarrazac (dir.) Léxico del drama moderno y contemporáneo. México: Paso de Gato, 57-61.

» Gontarski, S. "Samuel Beckett: hacia una crítica menor" en (2015) Beckettiana, $\mathrm{N}^{\circ} 14,7-17$.

» Gordon, L. “Krapp's Last Tape: A new Reading”. en (1990). Journal of Dramatic Theory and Criticism. N², 97-110

" Hausbi, K. y F. Heulot “Monólogo". en (2013) J.P. Sarrazac (dir.) Léxico del drama moderno y contemporáneo. México: Paso de Gato, 137-141.

" Henning D., S. "Narrative and Textual Doubles in the Works of Samuel Beckett”. en (1980). Substance. $\mathrm{N}^{\circ} 4$, 97-104.

» Iwata, M. "Records and Recollections in 'Krapp's Last Tape'” en (2008) Journal of Irish Studies, Vol.23, 34-43.

» Kakiguchi, Y. "The Inevitable Destruction of the Mediated Self: The Future Dead Tape-recording and Tape recorded in Beckett's Krapp's Last Tape”. En (2004) Osaka Literary Review. $\mathrm{N}^{\circ} 43,153-163$.

» Kintzele, P. "Sacrifice, Inhibition, and Oedipal Fantasy in Krapp's Last Tape" en (2009) Modern Drama, N², 207-219. 
» Knowlson, J. “'Krapp's Last Tape': the evolution of a play, 1958-1975” en (1976) Journal of Beckett Studies, $\mathrm{N}^{\circ}{ }_{1}, 50-65$.

»Lawley, P. “Stages of identity: from Krapp's last tape to Play" en (1994). J. Pilling (Ed). The Cambridge Companion to Beckett. Cambridge: Cambridge University Press, 88-104.

»Locatelli, C. “Projections: Beckett's Krapp's Last Tape and Not I as Autobiographies” en (2008) Ben-Zvi, L. y Moorjani, A. (Eds). Beckett at 100. Nueva York: Oxford University Press, 68-80.

" Losco, M. "Cuadro". en (2013) J.P. Sarrazac (Dir.) Léxico del drama moderno y contemporáneo. México: Paso de Gato, 68-70.

" Malkin, J. "Matters of Memory in Krapp's Last Tape and Not I" en (1997) Journal of Dramatic Theory and Criticism, $\mathrm{N}^{\circ} 2,25-39$.

»Prado, G. "Configuraciones temporales y función narrativa en el teatro beckettiano" en (2015) Beckettiana, $\mathrm{N}^{\circ}{ }_{14}$, 53-62.

» Ryngaert, J.P. (2016). El personaje teatral contemporáneo: descomposición, recomposición. México: Paso de Gato.

» Rojas, S. "La escritura del cogito: una hipótesis sobre Samuel Beckett." en (2013). Aisthesis, № 54, 39-54.

»Rauschenberg, N. "Memoria (in)voluntaria y mal de archivo en Proust y Beckett" en (2017) Crítica Cultural. N ${ }^{\circ}$, 115-122,

»Sarrazac, J-P. “Fábula (crisis de la)" en (2013) J.P. Sarrazac (dir.) Léxico del drama moderno y contemporáneo. México: Paso de Gato, 92-97.

"Sarrazac, J-P. “Personaje (crisis del)” en (2013) J.P. Sarrazac (dir.) Léxico del drama moderno y contemporáneo. México: Paso de Gato, 167-172.

»Sarrazac, J-P. (2011) Juego de sueños y otros rodeos: alternativas a la fábula en la dramaturgia. México: Paso de Gato.

»Sarrazac, J-P. “El impersonaje” en (2006) Literatura: teoría, historia, crítica. N8, 353-369.

»Weiss, K. (2013). The plays of Samuel Beckett. Londres: Methuen.

"Wilson, S. “'Krapp's Last tape' and the mania in Manichaeism” en (2002) Samuel Beckett Today/ Aujourd'hui, Vol.12, 131-144.

»Wulf, C. "Desire for the other: obsession as failure/failure as obsession. Beckett's 'Krapp's Last Tape' and Bernhard's 'Minetti”' en (1993) Samuel Beckett Today/ Aujourd'hui, Vol. 2, 87-94. 